\title{
National Institute for Clinical Excellence guidance: too NICE to glycoprotein IIb/IIIa inhibitors?
}

The arrival of the National Institute for Clinical Excellence (NICE) in 1999 was greeted with suspicion by many clinicians who regarded it as the beginning of an era of overt health care rationing. From a cardiological perspective, this has not proved to be the case. The guidelines issued on implantable defibrillators, intracoronary stents, and glycoprotein (GP) IIb/IIIa inhibitors have been liberal and in the last instance surprising to many cardiologists. ${ }^{1}$ Given our original misgivings, it might seem churlish to complain about NICE's liberality, but an endorsement from NICE gives a treatment the appearance of an official seal of approval. This has important medico-legal implications and may also inhibit further research into the use and targeting of these compounds - no drug company is going to look such an attractive gift horse in the mouth and fund selective studies. Has NICE gone too far with GP IIb/IIIa inhibitors?

GP IIb/IIIa inhibitors are powerful antiplatelet agents that represent one of the most important and exciting advances in the treatment of coronary thrombosis. The growth in their use over the last few years has been explosive and the market in GP IIb/IIIa inhibitors is now worth around $\$ 500$ million a year in the USA alone. These agents have well established beneficial effects in limiting adverse events around the time of percutaneous coronary intervention in patients with stable angina and acute coronary syndromes. ${ }^{2-5}$ More recently these agents have moved out of the catheter laboratory setting and into the "medical" management of acute coronary syndromes in the coronary care unit. This wider usage is based upon the results of a number of trials that have been conducted without mandatory early angiography and revascularisation, comparing the addition of either a GP IIb/IIIa inhibitor or placebo to aspirin and heparin. ${ }^{6-10}$ There are variations between these trials in the drug used, dose, duration of treatment, and interventional policy (table 1).
Inevitably these trials contain a mixture of patients that underwent percutaneous coronary intervention (and would be expected to benefit) and those that did not (who might benefit). These studies do not provide any evidence that GP $\mathrm{IIb} / \mathrm{III}$ inhibitors reduce mortality in acute coronary syndromes, but the combined end point of death/ myocardial infarction is reduced in most trials. A recent meta-analysis of the trials showed a modest but significant decrease in 30 day death/myocardial infarction $(11.5 \% v$ $10.7 \%, \mathrm{p}=0.04) .{ }^{11}$ After examining this evidence (two negative studies, PARAGON B ${ }^{8}$ and GUSTO IV, ${ }^{10}$ could not be considered as they have yet to be published) NICE concluded that: "For high risk patients with unstable angina or non- $\mathrm{Q}$ wave myocardial infarction the intravenous use of the glycoprotein IIb/IIIa inhibitors, in addition to aspirin and low dose heparin is recommended" ${ }^{12}$ This implies that, independent of any other treatment, GP IIb/IIIa inhibitors improve prognosis in high risk patients with acute coronary syndromes. There are a number of problems with this.

\section{Underlying pathophysiology of acute coronary syndromes}

Firstly such an effect is unlikely given the underlying pathophysiology of the condition. Acute coronary syndromes are caused by thrombus formation on the basis of rupture or erosion of an inflamed atherosclerotic plaque. ${ }^{13}$ Treatment of this situation requires not only dissolution of the thrombus but also measures to "pacify" the plaque and to limit its encroachment on the arterial lumen. This is likely to include a combination of approaches including mechanical, antithrombotic and, in the future, antiinflammatory measures. It is extremely unlikely that limitation or even lysis of coronary thrombus by GP IIb/IIIa inhibitors would alone be a curative manoeuvre for patients with acute coronary syndromes.

Table 1 Summary of results of trials in acute coronary syndromes comparing the addition of a GP IIb/IIIa inhibitor or placebo to heparin and conventional treatment

\begin{tabular}{|c|c|c|c|c|c|c|}
\hline Study & Drug & Intervention policy & $\begin{array}{l}30 \text { day death } / M I \\
\text { placebo group } \\
(\%)\end{array}$ & Early PTCA +CABG & $\begin{array}{l}\text { Benefits in patients not having } \\
\text { early intervention } \\
\text { (30 day death } / M I \text { ) }\end{array}$ & $\begin{array}{l}\text { Benefits in patients } \\
\text { waiting for intervention } \\
\text { (death/MI) }\end{array}$ \\
\hline $\begin{array}{l}\text { PARAGON A } \\
\quad(\mathrm{n}=2282)\end{array}$ & $\begin{array}{l}\text { Low and high dose } \\
\text { lamifiban ( } 3-5 \text { days) }\end{array}$ & $\begin{array}{l}\text { Not for } 48 \text { hours unless } \\
\text { emergency }\end{array}$ & 11.7 & $\begin{array}{l}24.8 \% \text { total placebo } \\
29 \% \text { active } 24 \%\end{array}$ & $\begin{array}{l}\text { NO } \\
\text { placebo } 11.7 \% \\
\text { active } 11.3 \%\end{array}$ & $\mathrm{NO}$ \\
\hline $\begin{array}{l}\text { PARAGON B } \\
(\mathrm{n}=5225)\end{array}$ & $\begin{array}{l}\text { Low dose lamifiban } 72 \\
\text { hours }\end{array}$ & $\begin{array}{l}\text { Not for } 24 \text { hours unless } \\
\text { emergency }\end{array}$ & 12.8 & $\begin{array}{l}42 \% \text { total } \\
\text { no difference } \\
\text { placebo } v \text { active }\end{array}$ & $\begin{array}{l}\text { NO } \\
\text { placebo } 11.3 \% \\
\text { active } 10.8 \%\end{array}$ & $\mathrm{NO}$ \\
\hline $\begin{array}{l}\text { PURSUIT } \\
\qquad(\mathrm{n}=10948)\end{array}$ & Eptifibatide 72 hours & At physician's discretion & 15.7 & $\begin{array}{l}24.1 \% \text { total } \\
\text { placebo } 24.8 \% \text { active } \\
23.3 \%\end{array}$ & $\begin{array}{l}\text { NO } \\
\text { placebo } 15.6 \% \\
\text { active } 14.8 \%\end{array}$ & $\begin{array}{l}\text { YES } \\
\text { placebo } 4.4 \%^{22} \text { active } \\
3 . \%^{\star}\end{array}$ \\
\hline $\begin{array}{l}\text { PRISM PLUS } \\
(\mathrm{n}=1570)\end{array}$ & $\begin{array}{l}\text { Tirofiban minimum } 48 \\
\text { hours }\end{array}$ & $\begin{array}{l}\text { Encouraged between } 48 \\
\text { and } 96 \text { hours }\end{array}$ & 11.7 & $\begin{array}{l}53.8 \% \text { total } \\
\text { no difference } \\
\text { placebo } v \text { active }\end{array}$ & $\begin{array}{l}\text { NO } \\
\text { placebo } 10.1 \% \\
\text { active } 7.8 \%\end{array}$ & $\begin{array}{l}\text { YES } \\
\text { placebo } 3.8 \%^{22} \text { active } \\
1.8 \%^{\star}\end{array}$ \\
\hline $\begin{array}{r}\text { GUSTO IV } \\
(\mathrm{n}=7800)\end{array}$ & $\begin{array}{l}\text { Abciximab } 24 \text { or } 48 \\
\text { hours }\end{array}$ & $\begin{array}{l}\text { Not for } 2-3 \text { days unless } \\
\text { recurrent ischaemia }\end{array}$ & 8.0 & $\begin{array}{l}30 \% \text { total, } \\
\text { placebo } 30 \% \\
\text { active } 30 \%\end{array}$ & $\begin{array}{l}\text { NO } \\
\text { placebo } 8.0 \% \\
\text { active } 8.6 \%\end{array}$ & $\mathrm{NO}$ \\
\hline
\end{tabular}

${ }^{\star} \mathrm{p}<0.05$ 


\section{Role of early revascularisation}

Secondly, the beneficial role of early revascularisation has not been taken fully into account. The advantages of early revascularisation in patients with acute coronary syndromes have been demonstrated by the FRISC II trial. ${ }^{14}$ Unlike earlier studies comparing an initially conservative with an interventional strategy for patients with acute coronary syndromes (VANQWISH ${ }^{15}$ and TIMI IIIb $^{16}$ ), FRISC II avoided the problem of significant crossover from the conservative to the interventional arm and managed to compare groups with a real difference in rates of angiography and revascularisation ( $71 \% v 9 \%$ at 10 days). The study showed impressive clinical benefits associated with early intervention, including a significant decrease in total mortality at one year. ${ }^{17}$ Similar results have been recently reported in the TACTICS trial. ${ }^{18}$

We now know that patients with negative troponins and normal ECGs are at low risk $^{19}$ ( $<1 \%$ death/myocardial infarction at 30 days), do not require early angiography, and are most unlikely to benefit from adjunctive treatments such as GP IIb/IIIa inhibitors. High risk patients with raised troponins and/or ECG abnormalities seem to benefit from early revascularisation (percutaneous coronary intervention or bypass surgery). Since these patients will receive GP IIb/IIIa inhibitors at the time of (percutaneous) intervention, ${ }^{2-5}$ is there any evidence that they should also be administered at the time of presentation? There are two possible reasons for doing this. The first is to improve outcome independent of, and lessen the need for, revascularisation. However, none of the GP IIb/IIIa inhibitor trials has shown any significant difference in early revascularisation rates between the placebo and active groups (table 1), even in trials where the decision to perform angiography/ revascularisation was left entirely at the discretion of the physician. Furthermore, there is no evidence that the administration of a GP IIb/IIIa inhibitor produces significant benefit in patients that do not undergo early intervention (table 1). Even if clinicians remain unconvinced by the results of FRISC $\mathrm{II}^{13}$ and TACTICS ${ }^{18}$ and choose to adopt an ischaemia driven expectant approach, there is no evidence at present to support the use of GP $\mathrm{IIb} / \mathrm{III}$ a inhibitors in high risk patients treated medically without a clear plan to proceed to early revascularisation.

\section{The wait for angiography}

The second reason for administration of GP IIb/IIIa inhibitors at presentation is to limit adverse events during the wait for angiography. Access to early angiography is not available at present to the vast majority of patients with acute coronary syndromes in the UK. A recent registry reports that only $10 \%$ of patients have inpatient angiography and $6 \%$ inpatient revascularisation ${ }^{20}$ (compared with a mean of around $35 \%$ in the GP IIb/IIIa inhibitor trials). ${ }^{6-10}$ Given the under provision of angiographic facilities in the UK, there might be a role for GP IIb/IIIa inhibitors in high risk patients as a holding measure while awaiting angiography-the so-called "drip and ship" strategy. The problem in the UK is that the ship is likely to be a very slow boat indeed with waits of 1-2 weeks for inpatient angiography being far from uncommon. While some trials have shown clear early benefit from GP IIb/IIIa inhibitors in terms of a reduction in progression to myocardial infarction before angiography, ${ }^{692122}$ others have not. ${ }^{7810}$ Furthermore, the period before angiography in the published studies is far shorter than is common in the UK. Consequently their relevance to patients who have to wait longer is unclear.

The European Society of Cardiology guidelines ${ }^{23}$ recommend continuing treatment daily until revascularisation but do not mention the maximum period for which GP IIb/IIIa inhibitors can be safely administered. The

\section{Trial acronyms}

CAPTURE: Chimeric 7E3 Antiplatelet Therapy in Unstable angina Refractory to standard treatment

EPIC: Evaluation of c7E3 Fab in the Prevention of Ischemic Complications

EPILOG: Evaluation in PTCA to Improve Long term Outcome with abciximab GP IIb/IIIa blockade

EPISTENT: Evaluation of Platelet GP IIa/IIIb Inhibitor for Stenting

FRISC: Fragmin during Instability in Coronary artery disease

GUSTO: Global Use of Strategies To open Occluded coronary arteries

PARAGON: Platelet IIb/IIIa Antagonist for the Reduction of Acute coronary syndrome events in a Global Organization Network

PRAIS-UK: Prospective Registry of Acute Ischaemic Syndromes in the UK

PRISM-PLUS: Platelet Receptor Inhibition in ischemic Syndrome Management in Patients Limited by Unstable Signs and symptoms

PURSUIT: Platelet glycoprotein IIb/IIIa in Unstable ngina: Receptor Suppression Using Integrilin Therapy.

TACTICS: Treat angina with Aggrastat and determine cost of therapy with an Invasive or Conservative Strategy

TIMI: Thrombolysis In Myocardial Infarction

VANQWISH: Veterans' Affairs Non-Q Wave Infarction Strategies in Hospital

existing trial evidence does not tell us whether GP IIb/IIIa inhibitors should be given every day during a 7-14 day wait for angiography or for a few days at presentation or confined to immediately before angiography. It is reasonable to suppose that the incidence of side effects might rise sharply with prolonged GP IIb/IIIa inhibitor administration and the costs would be considerable. NICE estimates the annual cost of the introduction of GP IIb/IIIa inhibitors at $£ 17$ million, ${ }^{12}$ but clearly if these agents are given for 10 days as opposed to $2-3$ days, this would rise to around $£ 60$ million. Rather than issue blanket approval it might have been wiser of NICE to commission trials to delineate the optimum timing and duration of administration of GP IIb/ IIIa inhibitors before angiography in the UK setting.

The NICE guidance on GP IIb/IIIa inhibitors suggests to clinicians that these agents provide benefit in high risk patients with acute coronary syndromes independent of any other treatment. The evidence for this is far from overwhelming. These important and powerful drugs should be deployed as part of an overall treatment plan, including early angiography and revascularisation. New drugs receive powerful advocacy from pharmaceutical companies but sometimes the case for the appropriate infrastructure in which to use them is less well made. NICE has the opportunity when reviewing its guidance next year to place the use of GP IIb/IIIa inhibitors within a coherent treatment strategy for acute coronary syndromes. If this opportunity is taken we will move a step closer to clinical excellence and begin to improve the outcome of patients with acute coronary syndromes.

CHARLES J KNIGHT

London Chest and King George Hospitals,

Bonner Road,

London E2 97X, UK

knightlch@aol.com 
1 Smith R. The failings of NICE. BMf 2000;321:1363-4.

2 EPIC Investigators. Use of a monoclonal antibody directed against the platelet glycoprotein IIb-IIIa receptor in high-risk coronary angioplasty. $N$ Engl F Med 1994;330:956-61.

3 CAPTURE Investigators. Randomised placebo-controlled trial of abcixmab before and during coronary intervention in refractory unstable angina: the CAPTURE study. Lancet 1997;349:1429-35.

4 EPILOG Investigators. Platelet glycoprotein IIb-IIIa receptor blockade and low-dose heparin during percutaneous coronary revascularization. $N$ Engl F Med 1997;336:1689-96.

5 EPISTENT Investigators. Randomised placebo-controlled and balloonangioplasty controlled trial to assess safety of coronary stenting with the use of platelet glycoprotein IIb-IIIa blockade. Lancet 1998;352:87-92.

6 PRISM-PLUS Investigators. Inhibition of the platelet glycoprotein IIb-IIIa receptor with tirofiban in unstable angina and non-Q wave myocardial infarction. N Engl f Med 1998;338:1488-97.

7 PARAGON Investigators. International randomised controlled trial of lamifiban (a platelet glycoprotein IIb-IIIa inhibitor), heparin or both in unsta-

8 Kleiman NS, Califf RM. Results from late-breaking clinical trials at ACCIS 2000 and ACC 2000. 7 Am Coll Cardiol 2000;36:310-25.

9 PURSUIT Investigators. Inhibition of platelet glycoprotein IIb-IIIa with eptifibatide in patients with acute coronary syndromes. N Engl f Med 1998; 339:436-43.

10 Verheugt FWA. Hotline sessions at the 22nd European Congress of Cardiology. Eur Heart J 2000;21:1984-8.

11 Bhatt DL, Topol EJ. Current role of glycoprotein IIb-IIIa inhibitors in acute coronary syndromes. $\mathcal{F} A M A 2000 ; 284: 1549-58$.

12 NICE. Guidance on the use of glycoprotein IIb-IIIa inhibitors in the treatment of acute coronary syndromes. National Institute for Clinical Excellence technology appraisal guidance No. 12. London: NICE, September 2000.

13 Davies MJ. The pathophysiology of acute coronary syndromes. Heart 2000; 83:361-6.

14 FRISC II investigators. Invasive compared with non-invasive treatment in unstable coronary artery disease. Lancet 1999;354:708-15.
15 Boden WE, O'Rourke RA, Crawford MH, et al. Outcomes in patient with acute non-Q wave myocardial infarction randomly assigned to an invasive as compared with a conservative management strategy. VANQWISH trial. N Engl f Med 1998;338:1785-92.

16 TIMI IIIB investigators. Effects of tissue plasminogen activator and a comparison of early invasive and conservative strategies in unstable angina and non-Q wave myocardial infarction. Circulation 1994;89:1545-56.

17 Wallentin L, Lagerqvist B, Husted S, et al for the FRISC II investigators. Outcome at 1 year after an invasive compared with a non-invasive strategy in unstable coronary-artery disease: the FRISC II invasive randomised trial. Lancet 2000;356:9-16.

18 Cannon CP, Weintraub WS, Demopoulos C, et al. Invasive versus conservative strategies in unstable angina and non-Q-wave myocardial infarction following treatment with tirofiban: rationale and study design of the international TACTICS-TIMI 18 trials. Am f Cardiol 1988;82:731-6.

19 Hamm CW, Goldmann BU, Heeschen C, et al. Emergency room triage of patients with acute chest pain by means of rapid testing for cardiac troponin T or troponin I. N Engl f Med 1997;337:1648-53.

20 Collinson J, Flather MD, Fox KAA, et al. Clinical outcomes, risk stratification and practice patterns of unstable angina and myocardial infarction without ST elevation: prospective registry of acute ischaemic syndromes in the UK (PRAIS-UK). Eur Heart 7 2000;21:1450-7.

21 The CAPTURE investigators. Randomised placebo-controlled trial of abciximab before and during coronary intervention in refractory unstabel angina: the CAPTURE study. Lancet 1997;349:1429-35.

22 Boersma E, Akkerhuis M, Theroux P, et al. Platelet glycoprotein IIb-IIIa receptor inhibition in non-ST segment elevation acute coronary syndromes: early benefit during medical treatment only, with additional protection during percutaneous coronary intervention. Circulation 1999; 100:2045-8.

23 Bertrand ME, Simoons ML, Fox KAA, et al. Management of acute coronary syndromes: acute coronary syndromes without ST segment elevation. Recommendations of the task force of the European Society of Cardiology. Eur Heart $\mathcal{F} 2000 ; 21: 1406-32$.

\section{IMAGES IN CARDIOLOGY}

\section{Sinus of Valsalva aneurysm rupture into the left atrium}

A 65 year old woman underwent routine transthoracic echocardiography for assessment following repeat left atrial myxoma excision 12 years after first recurrence. The transthoracic echo revealed a shunt between the left atrium and aorta. This lesion was further assessed with a transoesophageal echo which confirmed a coronary sinus fistula into the left atrium without dilatation of the sinus itself. There was no evidence of any other abnormality associated with aneurysms of the sinus of Valsalva. The aortic leaflets were normal with no aortic regurgitation. The left atrium was mildly dilated, there was trivial mitral regurgitation, and left ventricular function was unimpaired. She remains very well with no signs of left ventricular dysfunction and a normal exercise tolerance.

Aneurysms of the sinus of Valsalva, also known as coronary sinus fistula, are rare and usually rupture into the right chambers of the heart. they arise from thenon-coronary

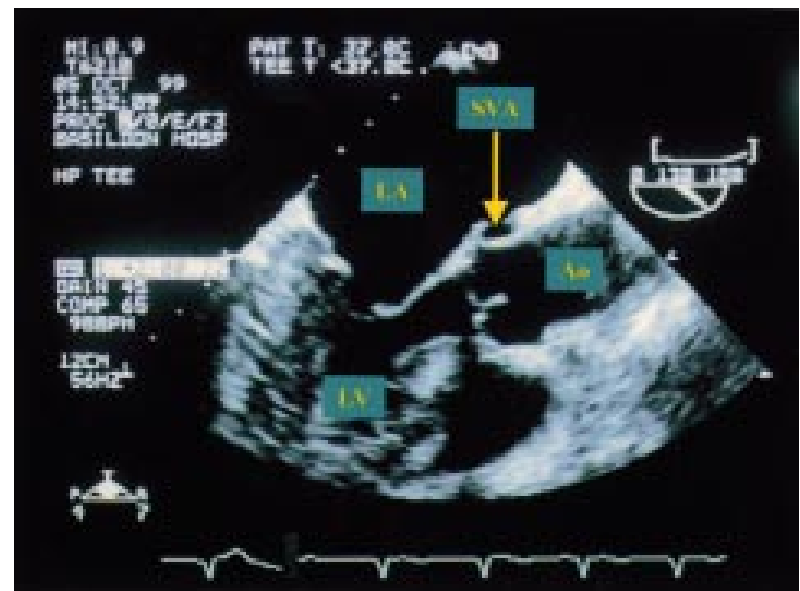

sinus in about $25 \%$ of cases and rupture more frequently into the right ventricle or right atrium. However, perforation may occur into the left ventricle, interventricular septum, pulmonary artery, superior vena cava, pleura or pericardium. There is a male predominance and an association with ventricular septal defect, aortic regurgitation, pulmonary stenosis, and membranous subaortic stenosis.

Most aneurysms are thought to be congenital in origin, arising because of the discontinuity between aortic tunica media and aortic valve annulus. The occurrence of the sinus of Valsalva aneurysm may well have been coincidental, rather than caused by the two procedures for atrial myxoma excision.

MANAS SINHA SUDHA IYER RAJESH AGGARWAL manas@msinha.freeserve.co.uk

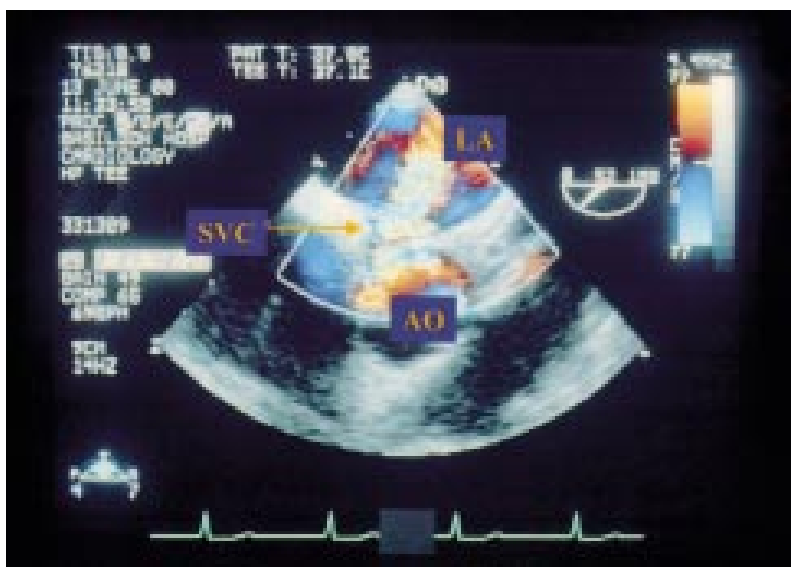

